\title{
Enhancing the employee engagement through the organizational climate (a study of school of business and management)
}

\author{
Hary Febriansyah \\ School of Business and Management, Institut Teknologi Bandung, Indonesia \\ Dematria Pringgabayu \\ Politeknik Pajajaran ICB Bandung, Indonesia \\ Nurfaisa Hidayanti \\ School of Business and Management, Institut Teknologi Bandung, Indonesia \\ Feny Citra Febrianti \\ Faculty of Psychology, Padjajaran University, Indonesia
}

\author{
Keywords \\ Employee Engagement, Organizational Climate, Reward and Punishment, Risk-Taking Educational \\ Staff
}

\begin{abstract}
Higher education is critical to economic success and long-term sustainability of Indonesia; a country in the South-East Asia region that is facing several challenges of economic growth and human capital capability, by employee engagement term. This study aims at determining the impact and the influence of the organizational climate on employee engagement. The study was from 50 educational staffs (staff, managers and school administrator) in the School of Business and Management. The employees are in the engaged state, whether they have deliver best performance, put out the best ideas, have a sincere commitment to the success of the organization and are willing to stay with the organization in the long term. The methodology used in this study is a mixed method, which to obtain more comprehensive objective analysis. The results show that organizational climate is one of the determining factors of employee engagement. Meanwhile, when it addresses partially from the eighth dimension that is in the organizational climate, there are the dimensions of rewards and punishments, risk-taking and identity of the organization that have a significant effect in creating employee engagement.
\end{abstract}

Corresponding author: Dematria Pringgabayu

Email addresses for corresponding author: demabayu5@gmail.com

First submission received: 23rd May 2017

Revised submission received: $25^{\text {th }}$ September 2017

Accepted: $20^{\text {th }}$ October 2017

\section{Research}

Higher education is critical to economic success and long-term development of Indonesia; a country in the South-East region that is facing several challenges of growth and development on many aspects, especially on human capital. The higher education provides economic and social benefits, both to the individuals and the public. In modern organizations and digital era today, employees are expected to be proactive and show initiative, collaborate smoothly with others and be committed to high quality performance standards and to be responsible for their own professional development (Bakker and Schaufeli, 2008). These organizations need employees who feel energetic and dedicated, and who are absorbed to their work. In other words, organizations need engaged workers.

Employee Engagement is a major factor contributing to organizational productivity, performance and long-term survival (e.g., Nowack, 2006). Organizations with highly engaged employees tend to show greater profits (Woodruffe, 2006) and turnover (Harter et al.2003). The other researcher (Wasilowski, 2016) states as well that employee engagement has a direct impact on the employee's productivity and hence on the productivity of the entire organization. This becomes truer for the educational institution since they 
are heavily human resource driven however, many Higher Education institutions are not fully focused on investing in employee engagement (Ellucian, 2013).

Most often engagement in higher education focuses efforts on faculty and staff development. In the broader context, engagement involves a unified recruitment, onboarding, retention and succession strategy of staff and faculty. Measuring, managing, and actively improving engagement is directly linked to business outcomes, and is essential to Universities competing in today's economy. However, there are only $34 \%$ of university faculty and staff are engaged in their jobs (Gallup, 2017).

School of Business and Management on this research is one of school in an entrepreneurial university in Indonesia. It has been established on 2013 and has been transforming from government management style, to the state own enterprises. There are some critical issues beyond this transformation, especially to human capital handling. Therefore, this study will answer the questions according to related issues above: (1) what is the existing level of engagement for the educational staffs? (2) What are the factors that possess important roles in affecting the level of engagement and organizational climate in this school? (3) How do the Organizational Climate and Psychological Climate affect the engagement of educational staff?

\section{Literature Review}

\subsection{The Concept of Organizational Climate}

The following are several definitions of organizational climate based on several experts and researches that are quoted from various literatures.Litwin and Stringer (1968, inHolloway, 2012: 13). "Organizational Climate is the set of measurable properties of the work environment that is either directly or indirectly perceived by the employees who work within the organizational environment that influences and motivates their behaviour.

According to Aishwarya and Ramasundaram (2011, cited in Kanten and Ülker, 2013) "Organizational Climate is defined as the recurring patterns of behavior, attitudes and feelings that characterize life in the organization more related to atmosphere and values".

Suarez et al. (2013) explained that based on previous empirical researches, there were several concepts as the outcomes of the members' perception on the organizational climate in their organization, they were work satisfaction, commitment, psychological well-being, employee attendance levels, psychosocial risk or violence at the workplace.

Some characteristics have been proposed by experts in reviewing the factors in organizational climate. Litwin and Stringer (in S. J. Yoo et al., 2012) developed an organizational climate measuring tool called Litwin and Stringer's Organizational Climate Questionnaire. This tool employs eight organizational climate factors, such as: 1) structure, which is the employees' views on the rules, procedures, and policies applied in the organization, and the limitations given by superiors or the organization. 2) Responsibility, which is the employees' views on the feeling of responsibility that grows in the organizational environment; How the employees' level of commitment towards the completion of tasks and work-related problems and the quality of the work result.3) Rewards and Punishments which is the employee's views on the systems of rewards and punishment applied in the organization. 4) Risk taking which is the employee's views on the organizational policies on how much was the trust given to the employees to take risks on making decisions, stemming from the chance to channel the employee's ideas and creativity. 5) Warmth and support which is the view towards the atmosphere of social interaction between members in the organizational environment. 6) Work standards and targets which is the views on the clarity of the organization's expectations towards the employees' work performance and how the work process and results must be fulfilled by the individuals or team. 7) Conflict Resolution which is the views of employees towards the skills of organization's members in resolving conflicts, and views towards the wisdom of superiors and organization to solve emerging conflicts. 8) Organizational identity which is the views on the importance and loyalty towards the organization and work team, including pride of being a part of the organization.

\subsection{The Concept of Employee Engagement}

Employee engagement is a theme that seeks to measure how far is someone's totality and involvement towards his/her work. This concept has developed alongside the development of positive 
psychology. Schaufeli et al. (2002, p. 74) define engagement "as a positive, fulfilling, work-related state of mind that is characterized by vigor, dedication, and absorption." They further state that engagement is not a momentary and specific state, but rather, it is "a more persistent and pervasive affective-cognitive state that is not focused on any particular object, event, individual, or behavior" (p. 74).

According to Schaufeli et al. (2002), vigor is characterized by high levels of energy and mental resilience while working, the willingness to invest effort in ones work and persistence in the face of difficulty. Dedication is ones" sense of significance, enthusiasm, inspiration, pride and challenge. Absorption refers to the state in which one is highly concentrated and happily engrossed in works so that $\mathrm{s} /$ he feels time passes quickly and it is difficult to detach from work.

It will also measure an individual's involvement on his/her work with all its' dynamics. Saks (2006 in Rasheed et al., 2013) concluded that the employee engagement is a construct that consists of cognitive, emotional, and behavioral components related to an individual's performance. The employee engagement can correlate on how high is the employee's totality towards his work. It has implications on an employee's performance, however energy and focus towards work are attached to the employee engagement that can make the employees exert their full potential towards work. Employee engagement can be also as extra-role performance. The positive emotions built in employee engagement will improve flexibility, creativity, integrity, and efficiency. (Saks 2006).

\subsection{Climate as the antecedent of Employee Engagement}

Bakker, Albrecht and Leiter (2011) explained that engagement level among employees are enhanced when employees experience trust, respect and mutual benefit. Employee's perceptions about organization create belief that the organization has the potential to treat them fairly, equally also able to facilitate growth and opportunity. Similarly, Albrecht (2010) found that employees, who feel they can trust and rely on others within the organization, feel more confident about taking risks and achieving their goals. Consequently, they are likely to give greater cognitive and emotional investment into their job roles, thereby experiencing increased employee engagement.

\section{Research Methodology}

The research employed the mixed method approach which combines the qualitative and quantitative methods (Creswell, 2010:5). According to Sugiyono (2011:18), mixed method combines two research methods at once: qualitative and quantitative, to obtain more objective and comprehensive analysis. The authors employed this approach in proportionate levels to understand the phenomena being researched.

\section{Participants}

The research has been enacted in the environment of School of Business and Management, Institut Teknologi Bandung in the city of Bandung, Jakarta, and Jatinangor campus. While the research conducted from February to July 2016 for 50 employees in total.

\section{Instruments}

In gathering quantitative data, the research team compiled two questionnaires consisting of 37 statement items, 18 items statement to explore eight aspects of organizational climate variables and 12 item statements to explore 7 aspects in employee engagement variables.

Both instruments have passed the test of validity and reliability to 50 respondents. By considering the alpha value of $5 \%$ of the number of respondents 50 people, obtained the value of product moment table correlation of 0.297 . For the organizational climate questionnaire, the $r$ count ranges from 0.299 to 0.748 . As for the employee engagement questionnaire, $r$ count ranges from 0.329 to 0.659 . Thus, it can be concluded that all items in both questionnaires are valid. For reliability testing, the reliability of a variable construct is said to be good if it has a Cronbach's Alpha value> 0.60 (Simamora, 2004: 177). The organizational climate questionnaire has a Cronbach's Alpha value of 0.635 and the employee engagement questionnaire has Cronbach's Alpha 0.687 so it can be concluded that both instruments are reliable.

\section{Procedure of Data Collection}

In collecting data, the research used population technique where the quantitative respondents were permanent full-time educational staff (Civil Servant (PNS)/Permanent by ITB (BHMN)/Permanent by SBM) who have worked for at least one year. 
On the other hand, researcher team arrange an interview protocol which used to dig up eight (8) organizational climate aspect and seven (7) employee engagement aspect. The informants were the Section Chief, Sub-Section Chiefs, Managers, Secretaries of Study Programs and several staff from each work unit that were chosen by the Section Chief/Sub-Section Chiefs/Managers. A thematic analyse to plot factors on each organizational climate aspect are held from 21 interview respondent result as real condition which occur in SBM-ITB. Moreover, all of those data are tested using triangulation technique to ensure the answer consistency between several respondent. So it can be declared that the information from respondents are valid to represent research population.

\section{Discussion}

\subsection{Discussion of Organizational Climate on Educational Staff}

Based on Litwin and Stringer (1968) theory, the perception toward organizational climate cannot be discussed as unity as organizational climate however it should be elaborated one by one for each aspect. The elaboration from data analysis shows that aspects perceived as favorable were responsibility, organizational identity, rewards, and warmth and support. The aspects perceived as unfavorable were structure and punishment. The aspects perceived to be neutral were risk taking, work standards and targets, and conflict resolution.

A. The valuation of responsibility as favorable indicates the existence of clear instructions and limitations as well as continuous supervision, however still providing the adequate amount of autonomy to carry out tasks and solve existing problems. Lockwood (2007, in Robertson-Smith G et al., 2009) suggests that organisations who build a culture of meaningfulness are more likely to have engaged employees. It is important that the task is challenging, offers some autonomy and ownership, has clearly defined goals, is creative and varied, demands both routine and new skills, and has some influence and ownership over the work. Educational staff stated that the condition that makes the responsibility aspect to be favorable are the chance to learn new things; Flexibility and autonomy in completing tasks; and presence of proportional instructions from superiors.

B. The level of pride on the institution has seen as favorable. The opportunity to learn and the quality of the organization fostered the educational staff to be pride for working at this school. The favorable valuation is shown on their perception towards the organization for being a quality organization which gave them opportunities to enrich their knowledge, which in turn will foster a sense of development in the educational staff while working at this school.

C. The perception of favorable meant that the educational staff has valued the rewards they receive as proportionate to their efforts. From the results of the interview it is seen that the educational staff puts emphasis on financial rewards. The educational staff has perceived that the financial rewards given by the organization is proportionate to their efforts at work. However, in the Jakarta campus, the valuation regarding financial rewards was unfavorable, where the salary standard in this school was inadequate compared to the living costs in Jakarta and the high level of workforce competition market.

D. Social support is also one of the study by Schaufeli and Bakker (2004, in Saks 2006) found that a measure of job resources that includes support from colleagues predicted engagement. A lack of social support has also consistently been found to be related to burnout (Maslach et al., 2001 in Saks 2006). The educational staff perceived the feeling of warmth, support, and empathy from other staffs and superiors, especially in informal lives such as friendship and hobbies. Other than that, they also perceived that the work unit teams to be solid and complete each other. Both these things fostered a feeling of happiness on the staffs when they were in the environment of the school.

The aspect of (A) structure was perceived to be unfavorable by the educational staff, because of the numerous complaints regarding the structure on the organizational level, namely: (1) Existing job descriptions were not implemented in a normative manner because each staff tend to work based on experience and routine; (2) Uneven task distribution remains because a subjective or objective matter, thus a work load analysis for every work unit and rank for the educational staff of SBM-ITB needs to be conducted; (3)The lack of standard in business process of educational staff between units and sections that caused the staff to hand over responsibilities to one another (4) Socialization through e-mail and meeting 
was not in accordance to the situations and conditions of the educational staff. The condition that makes (B) the punishment aspect to be valued as unfavorable was the lack of clear rules for the disciplinary conduct of the educational staff, for example on the matters of latency, attendance and absentees. It is hoped that the punishment was given directly with proper methods and considerations and given consistently, so that they could cause deterrence and change the staff behavior.

Generally, the work standards and targets in SBM-ITB are still perceived as neutral, it means that there were positively perceived conditions leading to favorable valuation and negatively perceived condition leading towards unfavorable valuation. In this matter, SBM-ITB has set standards and targets perceived to be high enough by the educational staff and this is perceived as a positive matter by them. The clarity on work standards and targets that is given made the educational staff understand the goals at work. The obstacles are felt when facing tasks that have unclear workflows and processes, tasks requiring more manpower, and work targets related to other units.

On the conflict resolution aspect, it is seen that the working conditions in SBM-ITB is not rife with conflict. The question is whether the absence of conflict is caused by the unwillingness of staff to openly conflict each other or due to the good capabilities for conflict resolution was possessed by educational staff, superiors, and leaders.

\subsection{The Employee EngagementLevel}

After performing exploration study through references which based from academic and practice regarding several engagement model. Observing phenomena which occur in the field along with conducting deep discussion by means of stakeholders, accordingly the SBM-ITB research team attempt to formulate a distinctive engagement model.

Employee engagement is a psychological condition on organizational member which marked by (1) energy, (2) turnover intention, (3) endurance, (4) proactive behaviour, (5) constructive criticism (6) pride toward institution, and (7) promoting institution.

The employee engagement variable consists of 12 statements (see appendix 1), Figure 1 shows the results of the recapitulation of respondents' answers regarding employee engagement in SBM-ITB:

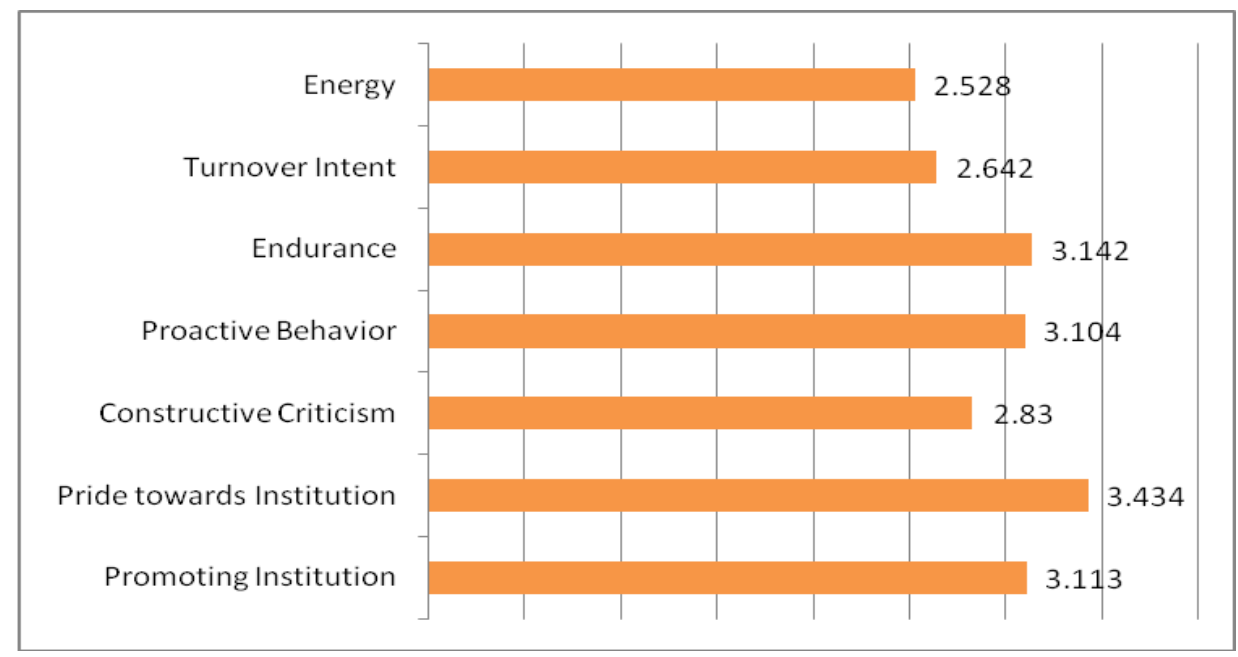

Figure 1. Respondent's Average Score for Employee Engagement Variable

The following are the general explanations of employee engagement based on the respondents' perspective:

\section{Pride towards Institution.}

The average total score is 3.434, aligned with the findings of qualitative analysis. The factor leading to this aspect is the different organizational characteristic compared to other faculties or schools in ITB. This proved that the rules, policies, and work processes were conducted with more autonomy, more professionally, and the better quality of human resources. The second factor is the feeling of security because of the employment status. 


\section{Endurance.}

The total score average is 3.142, aligned with the results of qualitative analysis. This means that generally the educational staff has quite a high level of endurance. The most contributively factor to the high level of endurance is tenure. Most respondents with high levels of endurance were educational staffs who worked for a long time in this school. Naturally, the respondents had really understood the business process flows, procedural standards, rules, policies, and the work culture dynamics and social issues of the environment. With knowledge and matured work experience, he/she knows very well of the proper behaviour and action patterns to be applied to face pressures or obstacles at work.

\section{Promoting Institution.}

The aspect is categorized as high with average score of 3.113.On the other side, the qualitative analysis showed that mostly the promoting institution aspect was at the average level. The affecting factors were that the social norms in the society that fostered the mind-set that promoting institution is identical to arrogance or bragging. The second, the exclusive image of SBM in the internal environment of ITB is still felt by the educational staff. This could lead into two things, first the educational staff felt reluctant to promote the positive things about SBM because of fear of backlash from colleagues in other faculties or the ITB central office. The other effect is that the staff who felt the pride thought that people they knew already knew about SBM-ITB.

\section{Proactive Behavior.}

The average total score is quite high which 3.104 reinforced by the results of qualitative findings is. The factors that cause the educational staff to act proactively was that the staff felt that he/she didn't have the authority to solve problems based on his/her own opinions. According to Maslach et al. (2001, in Saks 2006), lack of support from supervisors has been found to be an especially important factor linked to burnout. In addition, first-line supervisors are believed to be especially important for building engagement and to be the root of employee disengagement (Bates, 2004; Frank et al., 2004, in Saks 2006). Special for the educational staff in the executive levels or sub-section chief, they are conducting very routine and administrative routine work areas and authorities caused the thought patterns to be monotonous and rigid.

\section{Constructive Criticism.}

Feeling able to express and employ oneself without fear of negative consequences to self-image, status or career is another key determinant of engagement according to Kahn (1990, in Robertson-Smith G et al., 2009). This aspect had an average score of 2.83 , in alignment with the results of qualitative analysis. The factor, that can be mapped so that these conditions becomes more optimal, is the reluctance to express opinions towards the leader of the institution or even the direct superior is a factor that affected the courage of the educational staff to express constructive criticism.

\section{Turnover Intention.}

Schaufeli and Bakker (2004, in Saks 2006) found that engagement was negatively related to turnover intention and mediated the relationship between job resources and turnover intention. The resignation intent average score is 2.642 so that it is categorized as neutral. But the qualitative analysis showed that 15 out of 21 respondents had low intention to resign from SBM-ITB. Offers to work in other places do come to the educational staff, but this won't affect the educational staff's turnover intent significantly, only tempted temporarily.

\section{Energy.}

The average score is 2.528 so that this is included in the average level. According to Schaufeli (2002), vigor is characterized by high levels of energy and mental resilience while working, the willingness to invest effort in one's work, and persistence even in the face of difficulties. In psychology, the energy concept is analogous to a magnitude of mental and physical energy that affected someone's power at work. This energy magnitude is congenital, relatively will not change significantly throughout life. How to increase this is related to how energy is used more effectively to support productivity at work. The second factor is the importance to understand the personal interests, needs, and work styles of each educational staff and their alignment with their current work demands. Hopefully the alignment will encourage the educational staff to exert his whole work energy optimally. 


\subsection{The Relationship of Organizational Climate and Employee Engagement}

Organizational climate represents the condition of the organization's culture. The workforces today are filled with various mindsets. Over the past few years, there has been numerous support on Human Capital development, life-long learning and continuous attention on soft skill development (Permarupan et al, 2013). Limelight on enhancing employee performance needs to be at the top of every organization's climate. Nurturing a positive workforce climate is no longer seen as a simply an attractive option; it is a business vital. Climate has a tangible effect on employees' motivation. A good working climate boosts employee morale, loyalty and productivity (Permarupan et al, 2013). Organizational climate is deemed to be important: it is perceived, as motivated employee will result in higher productivity, greater passion for the business, and a deeper engagement with customers. A positive climate encourages employees' productivity and decrease turnover. The research found the top three employee engagement tactics being used within higher education were: clarity of role, setting performance expectations and regular appraisals. "Increasingly, higher education institutions are looking to find better ways to achieve alignment between these organizational goals and the contribution of the different faculties and departments, which have traditionally had a long history of autonomy"

The organizational climate consists of eight sub variables, and based on the results of simultaneous testing (t-test), they have a significant effect on shaping employee engagement. It means that the organizational climate is one of the shapers of employee engagement in SBM-ITB. Therefore, when the educational staff felt that the organizational climate in SBM-ITB was conducive and supportive enough towards the completion of tasks, they would feel more bonded to the organization. On the other hand, if we discuss the dimensions of organizational climate partially, there are only three dimensions that significantly affect in shaping the employee engagement in SBM-ITB, namely rewards and punishment, risk taking, and organizational identity.

In the matter of reward and punishment, SBM-ITB gave promotion to the educational staff that had potential and worked optimally, then the bonus and incentive were also given based on the proportion to the educational staff's work performance. Whereas, the punishment was considered not too harsh or flexible for the educational staff. Thus, it can be concluded that adequate rewards and relaxed punishment caused the educational staff to be engaged to the institution where they worked.

Discussing about the risk taking, one of the most interesting indicators for the educational staff was that the superiors or leaders in SBM-ITB who were happy to accept various new ideas and implement them as long as they can be implemented practically and giving benefits to the institution.

For the last, the organizational identity can also influence employee engagement. The organizational identity is related to the pride of being a member of SBM-ITB. The pride made the educational staff feel bonded and engaged.

\section{Conclusion}

The results generally showed that the employee engagement levels in SBM-ITB tends to be at high level (above 3 in a scale of 4). It means that the educational staff have good physical, cognitive, and psychological attachment towards the job and institution where they worked. The high physical attachment was shown by the willingness of educational staff to provide their best effort in completing the task, for example their capability to work deftly and swiftly and the capability to complete additional tasks beside their main tasks if it was needed. The high cognitive attachment was showed by their effort to learn how to complete new tasks effectively when rotation was conducted, or their effort to find another way to complete tasks and keep innovating. The high psychological attachment was showed by a strong belief that SBM-ITB as an institution has high quality, and the feeling of love and pride due to the part of SBM-ITB.

Based on the results, there were factors that could affect the engagement level of the educational staff in SBM-ITB, such as:

1. Age and tenure of working which made the employee's experience, knowledge, and the skills towards business process and work become mature in the institutional level. The maturity would equip the educational staff with the skills of setting work plans and improve their scale of 
priority. They eventually can manage their performance properly to face pressures and obstacles at work.

2. The alignment between personal interests and employee work style with the demands of the job. This alignment would encourage the staff to exert their performance optimally.

3. The pride towards institution which is affected by the staff perspective towards the institution's consistence in maintaining the characteristics of SBM-ITB, such as system, procedure, and characteristics, compared to the other schools and faculties in ITB.

4. The proactive behavior and the courage to deliver creative criticism; the courage to face tasks, challenges and new problems proactively and independently in accordance with an authority; the efforts to find the required information, map problems, various solution alternatives that are consulted with related parties.

5. Uniformity and the certainty about the promotion of permanent employee become an issue that affects the employee engagement level in SBM-ITB.

\section{References}

Aishwarya, B.\&Ramasundarum, G. (2011). Working Hours as an Influencing Factor Towards Workfamily Conflict of Women Employees in IT Sector of Chennai City. Tecnia Journal of Management Studies, 6 (2): 35-39

Albrecht, S. L., \& Albrecht, S. (2010). Handbook of employee engagement. Cheltenham: Edward Elgar Publishing Limited.

Bakker, A. B., Albrecht, S. L., \& Leiter, M. P. (2011). Key questions regarding employee engagement. European journal of work and organizational psychology, 20(1), 4-28.

Bogler, R., \& Somech, A. (2004). Influence of teacher empowerment on teachers' organizational commitment, professional commitment and organizational citizenship behavior in schools. Teaching and teacher education, 20(3), 277-289.

Creswell, J. W. (2010). Mapping the developing landscape of mixed methods research. SAGE handbook of mixed methods in social \& behavioral research, 2, 45-68.

Ellucian (2013). Empowering Employees: The state of employee engagement and student retention.

Gallup (2017). The Engaged University. Gallup Higher Education Employee Engagement.

Holloway, J. B. (2012). Leadership behavior and organizational climate: An empirical study in a non-profit organization. Emerging Leadership Journeys, 5(1), 9-35.

Kanten, P. and Ulker, E.F. (2013). The Macrotheme Review: A multidisciplinary journal of global macro trends. The Effect of Organizational Climate on Counterproductive Behaviors: An Empirical Study on the Employees of Manufacturing Enterprises, University, School of Tourism and Hotel Management, Burdur, Turkey.

Nowack, K. (2006). Employee engagement, job satisfaction, retention and stress. Retrieved from: www.envisialearning.com, accessed during April 2011

Permarupan, P. Y, Roselina, A.S, Kasimc, R.A, Balakrishnan, B.K.P.D. (2013). The Impact of Organizational Climate on Employee's Work Passion and Organizational Commitment. Procedia Social and Behavioral Sciences 107 (2013) 88 - 95

Robertson-Smith G., Markwick, C. 2009. Employee Engagement A review of current thinking. Institute for Employment Studies . University of Sussex Campus Brighton. UK

Saks, A. M. (2006). Antecedents and consequences of employee engagement. Journal of managerial psychology, 21(7), 600-619.

Schaufeli, W. B., Salanova, M., González-Romá, V., \& Bakker, A. B. (2002). The measurement of engagement and burnout: A two sample confirmatory factor analytic approach. Journal of Happiness studies, 3(1), 71-92.

Simamora, H. (1997), Manajemen Sumber Daya Manusia, Yogyakarta; STIE. YKPN

Steers, R. M., Ungson, G. R., \& Mowday, R. T. (1985). Managing effective organizations. Kent Pub. Co.

Suarez, E.P., Muniz, J., Alvarez-Campilo, A., and Cueto-Garica, E. (2013).Assessing organizational climate: Psychometric properties of the CLIOR Scale, Universidad de Oviedo and, Eduardo FonsecaPedreroUniversidad de La Rioja Psicothema 2013, Vol. 25, No. 1, pp: 137-144doi: 10.7334/psicothema2012.260; ISSN 0214 - 9915 CODEN PSOTEG 
Sugiyono. (2011). Metode Penelitian Kuantitatif Kualitatif dan R\&D. Bandung

Wasilowski, S. (2016). Employee Engagement in Higher Education: The financial impact of engagement in highereducation. Retrieved from https://works.bepress.com/stuart_wasilowski/12/download/, accessed September 2017

Widodo, F. A. S., \& Sami'an, M. (2013). Hubungan Employee Engagement dengan Perilaku Produktif Karyawan. Jurnal Psikologi Industri dan Organisasi, 2(1).

Woodruffe, C. (2006) "The crucial importance of employee engagement", Human Resource Management International Digest, Vol. 14 Issue: 1, pp.3-5, https:/ / doi.org/10.1108/09670730610643891 